\title{
Die Asepsie bei den alten Griechen.
}

Es gereicht mir zu besonderer Freude, dass die gehaltvolle Arbeit meines atheniensischen Gastfreundes Anagnostakis "über die antiseptische Metbode bei den alten Griechen" (Galen. März 1889) von meinem alexandrinischen Freunde Kartulis den Lesern dieser Wochenschrift in Erinnerung gebracht worden ist. (No. 49, 1889). Ich möchte nur noch den Anfang des Briefes beifügen, den mir Anagnostakis zugleich mit seiner Arbeit gesandt hat:

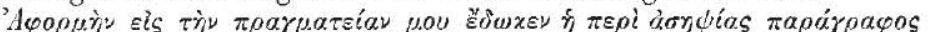

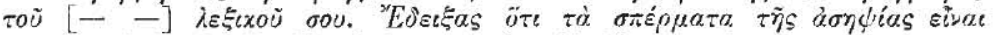

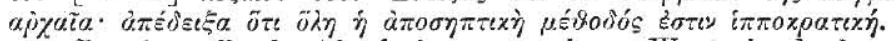

Der betreffende Abschnitt aus meinem Wörterbuch der Augenheilkunde (Leipzig. 1887, p. 7) lantet:

A sepsis, Asepsia = fäulnissfreies Verfahren, von $\dot{\alpha}$ - und $\sigma \tilde{\eta}$ dess. Aseptisch $=$ fäulnissfrei (ひ̋ $\sigma r \pi \tau o s$ scbon bei Hippocr., Foes. 532, 48). Die Lebre ist älter als man glaubt. Bereits Hippocr. (Littr.

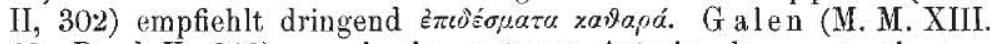
22; Band X, 942) umgab eine grössere Arterie, bevor er sie ausschnitt, oben wie unten mit einer Schlinge aus aseptischem Stoff,

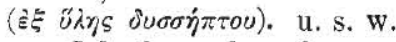

Ich bemerke, dass nach meiner Ansicht Name und Begriff der Asepsie besser ist als der der Antisepsis. 'A rycía ist ein

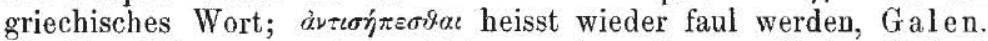
II, 21. Möge man aber nicht aus dem oben erwähnten Referat des Collegen Kartulis das Wort Aposepsis entnehmen und in

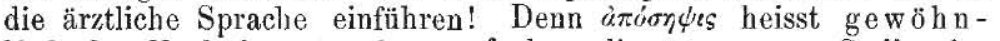

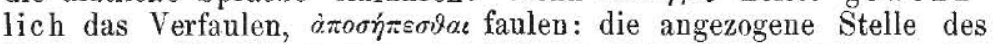
Hippocr. (de aëre 8, Littr. II, 36) ist entweder verdorben oder

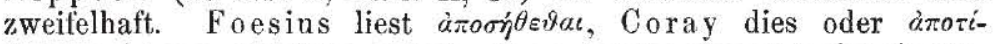

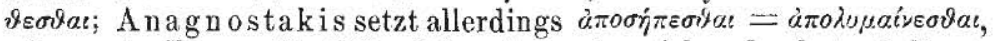
wie auch Foes. (I, 330, 37) schon das folgende hat, indicare potest à putredine vindicari.

J. Hirschberg. 